\title{
04 CONSEQUENCES OF HUSBAND PERPETUATED VIOLENCE AGAINST WOMEN ON CHILD HEALTH AND PSYCHO-SOCIAL STATE
}

doi:10.1136/injuryprev-2012-040590q.4

\begin{abstract}
${ }^{1 *}$ Anwar Kazi Selim, ${ }^{2}$ Yasmin Ahad, ${ }^{3}$ Begum Ayesha, ${ }^{4}$ Gani Nurul, ${ }^{5}$ Monwar S Reaz, ${ }^{6}$ Rahman Mahfuzur M Shah, ${ }^{7}$ Islam Khaleda, ${ }^{8}$ Karim S Afzalul, ${ }^{9}$ Sengupta Pradip Kumar, ${ }^{10}$ Molla Azaher Ali. ${ }^{1}$ Development Organization of Socio-economic, Health and Environmental Research (DOSHER), 701, Tongi Diversion Road, Moghbazar (Shifted at Punak Complex, 2nd Floor, 99/2, Moghbazar, Dhaka 1217, Bangladesh; ${ }^{2}$ Bengali Language, The British School, Dhaka; ${ }^{3}$ Faculty of Food Sc \& Tech, Chittagong Vet \& Animal Sc Univ; ${ }^{4}$ Inst. Pub Health \& EC-member, DOSHER; ${ }^{5}$ Child Right Div, ORNOB; ${ }^{6}$ FS, Inst. Public Health; ${ }^{7}$ Inst. of Nutr \& Food SC, Dhaka Univ; ${ }^{8}$ Dermatology, Holy Family Med College Hosp \& Finance Dir, DOSHER; ${ }^{9}$ IMPACT Foundation Bangladesh; ${ }^{10}$ Dept. Heath Economics, Dhaka Univ \& EC-Member, DOSHER. Dhaka, Bangladesh; $1{ }^{*}$ Recently joined as Coordinator, QI Program at the CIPRB, H\#B-162, Lane 23, New DOHS, Mohakhali, Dhaka 1206, Bangladesh)
\end{abstract}

Background The UN-Resolution defines violence against women-VAW as any-act of gender-based violence resulting in phys$\mathrm{ical} / \mathrm{sexual} / \mathrm{psychological-harm/threat} \mathrm{to} \mathrm{women,} \mathrm{coercion} \mathrm{or}$ arbitrary-deprivation of liberty, in her life. Despite several national/ global initiatives (Nairobi-Strategy'85,Beijing-Platform'95), promoting/ enforcing women's-rights remains slower. In Asia, prevalence/magnitude of VAW is being-rampant. Here, we present preliminaryfindings on family-violence (FV) from Bangladesh and its' negative-impact on child's health and psycho-social state.

Purpose Study occurrences of husband-perpetuated FV and assess its effect on child's health and psycho-social state (schoolperformances).

Methods This cross-sectional survey was conducted among 72 married-women living-in 64 households in randomly-selected three rural-villages. Adopting a 2-tier-methodology we interviewed all women using a pre-tested structured-questionnaire, and assessed their perception on-VAW, qualitatively (using FGDs, In-depthInterview/IDIs).

Outcome Of 72 women, $94 \%$ were less/ill-literate, $53 \%$ poor, majority being 1 st wives. Of $68 \%(n=49)$ with some-degree of familyviolence, $45 \%$ tolerated mild-form(mostly verbal and rarely physical abusing/slapping), 37\% endured moderate-form (verbal/physicalabusing 3-4 times/year) and 18\% sustained severe-form(physical torturing every1-2 weeks-apart) of VAW. While verbal-abusing was confined in rebuking/reprimand; physical-abuse ranged from scolding to battering: fist-hitting/hand-twisting, beating, punching, kicking/knocking. Few severe-cases sustained throat-grabbing/knifecharging/burnt-off body-parts/forced-sex and suicidal attempts. Attesting these findings, post-FGD/IDI-transcript analysis revealed dowry-demand, gross-poverty and/or husband-dependency was prime-causes of FV. But, FV-victims never raised voice to avoid social-chaos/gossip and/or pro-male(husband)-biased unfairjudgment(s). Severity of FV-cases was associated with child's health (pre-set-parameters), $(p<0.04)$ and school-performance $(p<0.03)$ including other psycho-social-state.

Significance/Contribution Occurrence of FV in rural-Bangladesh (breeching women-right) and exerting negative-impact on child's health/psycho-social state(violating child-right) remains imperative for immediate intervention towards stopping male-driven socio-cultural-epidemics right now if not possible to combat it instantly. 